\title{
PERKIRAAN NILAI TAMBAH YANG HILANG PADA AGROINDUSTRI KAKAO INDONESIA
}

\author{
Muhammad Basorudin \\ Banna Izzatul Hasanah \\ Indria Hartati \\ Politeknik Statistika STIS \\ Email: 14.8256@stis.ac.id
}

\begin{abstract}
As an agricultural country Indonesia has a lot of natural potential that can be used as export base, for example is cocoa. Unfortunately, most of the cocoa products are still exported in raw form. Even if, Indonesia also imports cocoa in the form of seeds or in processed form. As a result, there are muchlost value added of cocoa. The lost value added of cocoa is measured by the difference between processed cocoa and raw cocoa exports. The loss of added value can actually become Indonesia's revenue potential. The purpose of this research is to lose the added value of Indonesian cocoa products during the period 20092018. In addition, the lost value added of cocoa is also forecasted until the end of 2018. The technique used to forecast is by ARIMA method. It estimates that lost value added of cocoa every month until December 2018. The increase in lost valueadded will give benefit for Indonesianif they can undertake theirs own processing of cocoa products and publishing them to the international market in the form of processed product. Therefore, it is necessary to start to develop alternatives such as the development of production-based agroindustries, especially on the concept of cocoa, and the application of One Village One Product (OVOP) concept in order to increase cocoa productivity and minimize domestic competition..
\end{abstract}

Keywords:Cocoa export, Lost Value Added, ARIMA, Agroindustry, OVOP.

\section{PENDAHULUAN}

alam pembentukan pendapatan nasional, ekspor netto merupakan salah satu komponen yang sangat penting. Ekspor netto atau biasa disebut neraca perdagangan adalah selisih antara pendapatan yang diterima dari kegiatan ekspor dan pengeluaran dari kegiatan impor.

Nilai neraca perdagangan yang positif menunjukkan bahwa kegiatan perdagangan internasional suatu negara mengalami surplus, sedangkan 
nilai negatif menunjukkan bahwa perdagangan internasional mengalami defisit.

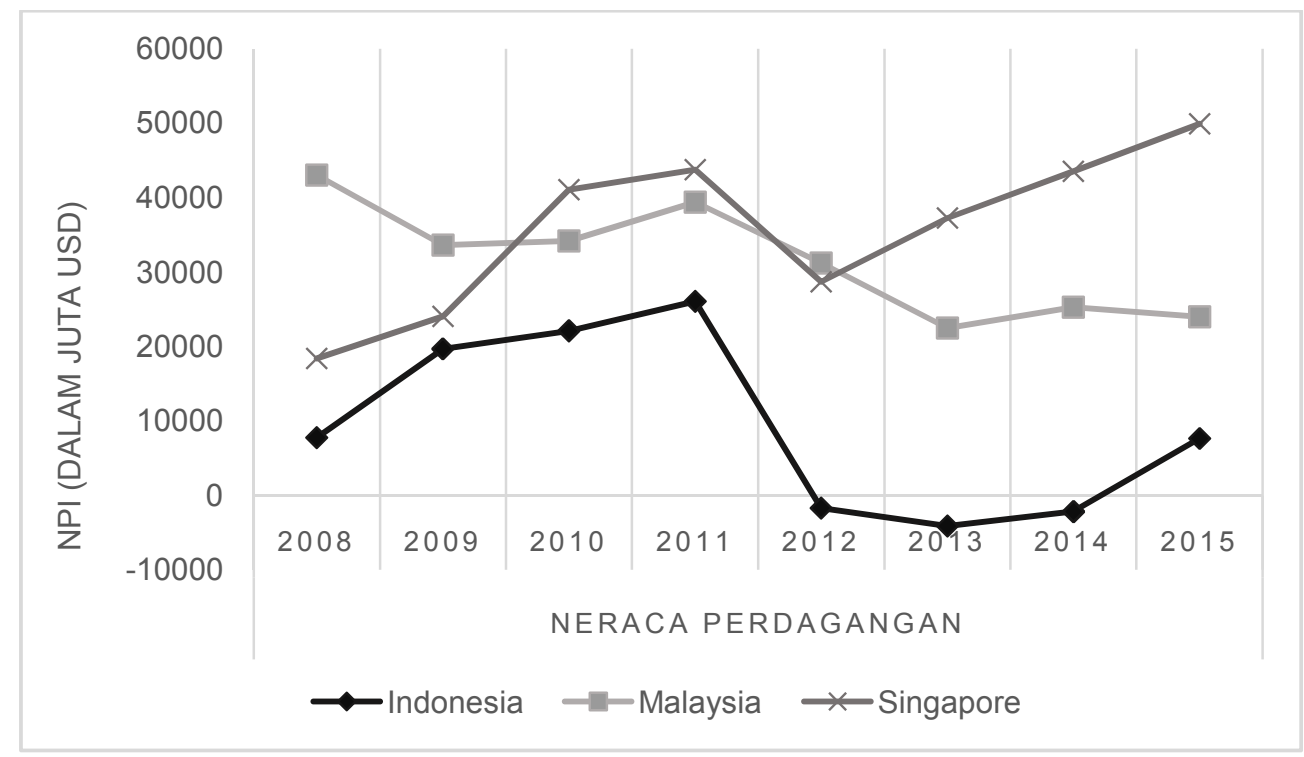

Sumber: World Integrated Trade Solution (WITS), 2018.

Gambar 1.Perkembangan Neraca Perdagangan Indonesia Tahun 2008-2015

Berdasarkan Gambar 1, dapat dilihat bahwa nilai neraca perdagangan Indonesia pada beberapa tahun terakhir menunjukkan angka yang sangat berfluktuatif. Angka tersebut bahkan menyentuh titik negatif pada periode tahun 2011-2013. Apabila dibandingkan dengan negara tetangga, seperti Malaysia dan Singapura, Indonesia masih berada di bawah kedua negara tersebut. Selama kurun waktu tahun 2008-2015, neraca perdagangan Malaysia dan Singapura selalu mengalami surplus, sedangkan Indonesia mengalami defisit neraca perdagangan, khususnya pada periode tahun 2012-2014.

Jika dilihat dari sisi pendapatan nasional, proporsi ekspor Indonesia menempati urutan kedua setelah konsumsi rumah tangga. Kondisi tersebut menunjukkan bahwa sebenarnya kinerja ekspor Indonesia sudah cukup baik. Sayangnya, meskipun pendapatan dari kegiatan ekspor cukup besar, impor yang dilakukan Indonesia juga masih tergolong tinggi. Berdasarkan Gambar 2 terlihat bahwa selisih antara pendapatan dari ekspor dan pengeluaran untuk impor sangat kecil, bahkan hampir sama pada tahun 2012-2014. Kondisi demikian pada akhirnya akan memberikan kerugian 
bagi Indonesia karena manfaat dari nilai ekspor yang tinggi hanya digunakan untuk menutup impor. Berdasarkan data BPS selama tahun 2017, proporsi neraca perdagangan terhadap Produk Domestik Bruto (PDB) konstan hanya 1,9 persen. Sumbangan tersebut tergolong sangat kecil terhadap perekonomian nasional. Bandingkan dengan negara tetangga seperti Singapura. Meskipun PDB Singapura lebih kecil dari Indonesia, akan tetapi proporsi neraca perdagangan sangat beda jauh. Berdasarkan Departement of Statistics Singapore, proporsi net export Singapura mencapai 28,15 persen dari nilai PDB pada tahun 2017. Rendahnya sumbangan net export Indonesia tentu tidak akan terlalu berdampak signifikan peningkatan pertumbuhan ekonomi. Untuk itu, perlu upaya untuk terus meningkatkan ekspor atau menurunkan impor agar net ekspor kembali meningkat.

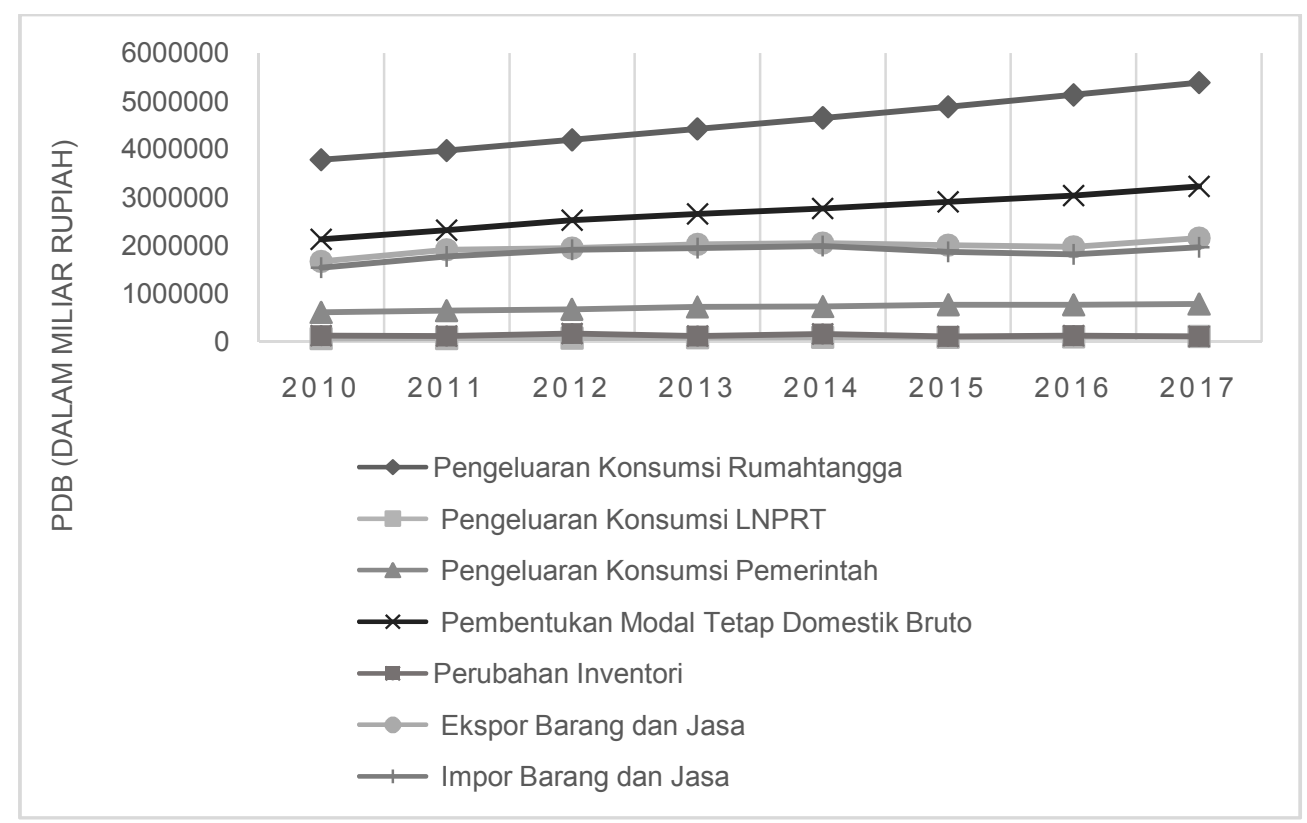

Sumber: Badan Pusat Statistik (BPS), 2018.

Gambar 2. Perkembangan Produk Domestik Bruto (Tahun Dasar2010) Indonesia Menurut Komponen Pengeluaran Indonesia Tahun 2010-2017

Secara umum, komoditas ekspor dibedakan menjadi migas dan nonmigas. Berdasarkan data BPS dari tahun 2010-2017, lebih dari 50 persen nilai ekspor Indonesia berasal dari komoditas nonmigas. Komoditas nonmigas sendiri terdiri dari tiga komoditas lagi, yaitu pertanian, pertambangan, dan 
industri pengolahan. Di antara ketiga komoditas nonmigas tersebut, komoditas industri pengolahan memberikan nilai ekspor tertinggi, sedangkan komoditas pertanian memberikan nilai ekspor paling kecil. Beberapa komoditas utama seperti kakao dan karet juga tidak memberikan dampak yang signifikan. Pada tahun 2015, sumbangan biji kakao terhadap total eskpor nasional tidak mencapai 1 persen. Bahkan, volume eskpor biji kakao cenderung menunjukkan tren penurunan sejak tahun 2009. Penurunan volume ekspor terbesar terjadi pada tahun 2014, yaitu turun sebesar 61,97 persen. Sumbangan karet terhadap total ekspor juga masih sekitar 2,67 persen. Sampai saat ini, ekspor Indonesia masih ditopang oleh minyak kelapa sawit (Crude Palm Oil) dengan proporsi 11,67 persen yang merupakan bukan produk sektor pertanian.

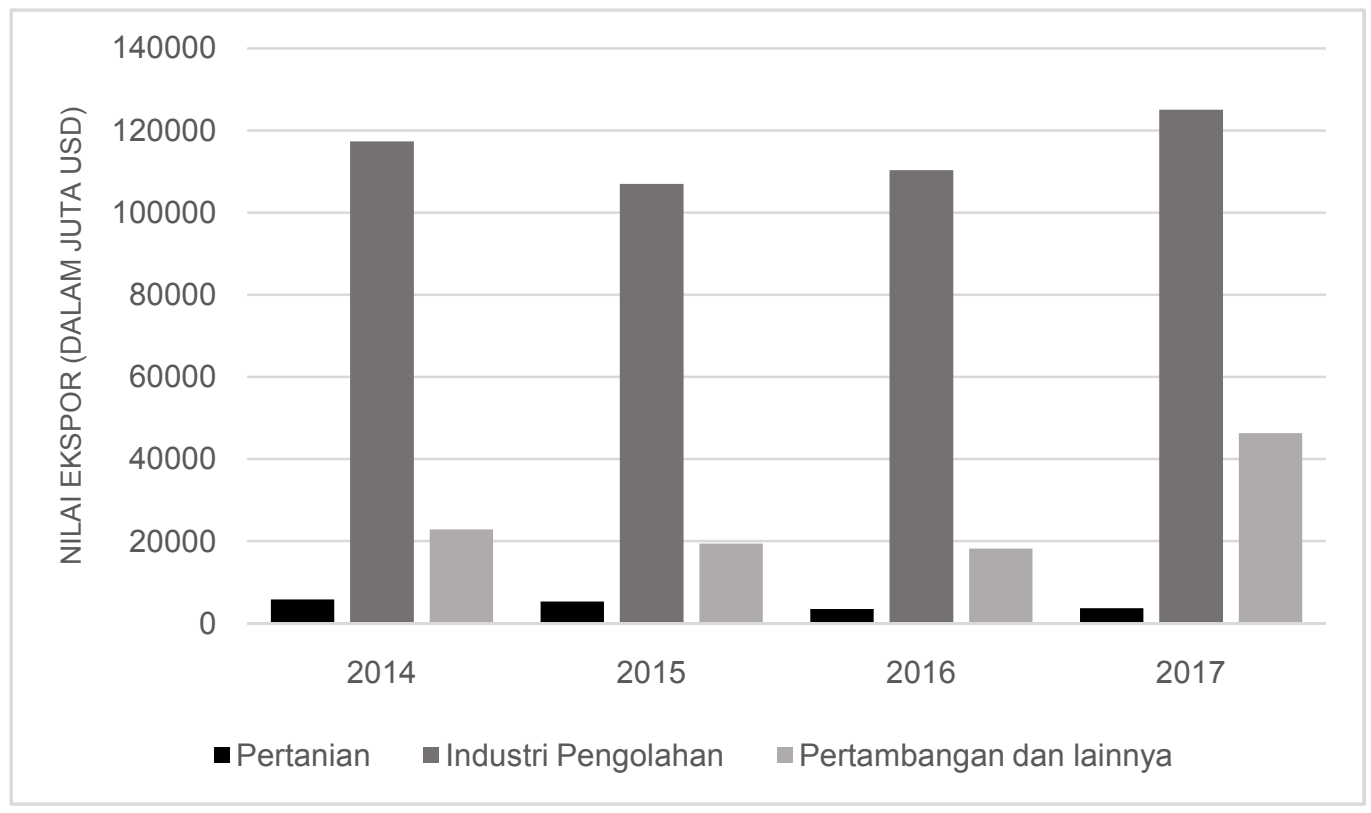

Sumber: BPS, 2018

Gambar 3.Nilai Ekspor Komoditas Nonmigas Indonesia Tahun 2010-2017

Sebagai negara agraris tentunya sumbangan output sektor pertanian terhadap perekonomian Indonesia sukup besar. Pada tahun 2017, sektor ini adalah sektor dengan distribusi terhadap PDB terbesar kedua, yaitu 13,14 persen, setelah sektor industri pengolahan. Jika dilihat dari jumlah tenaga kerjanya, jumlah tenaga kerja yang bekerja pada sektor pertanian adalah tenaga kerja dengan jumlah paling banyak, yaitu mencapai 39,7 juta orang 
pada Februari 2017 dan 35,9 juta orang pada Agustus 2017. Selain itu, berbagai produk komoditas pertanian Indonesia seperti karet, kakao, dan sawit menjadikan Indonesia sebagai salah satu eksportir terbesar di dunia. Kecilnya nilai ekspor dari komoditas pertanian salah satunya karena eskpor komoditas tersebut dalam bentuk bahan mentah, sehingga value added yang dihasilkan tergolong rendah.

Menghadapi hal demikian, sebenarnya Indonesia tidak perlu khawatir. Indonesia memiliki banyak potensi alam yang dapat dikembangkan sebagai basis ekspor, salah satunya adalah kakao. Sayangnya, selama ini sebagian besar produk kakao diekspor dalam bentuk mentah. Sekitar 67 persen kakao diekspor dalam bentuk biji ke Malaysia pada tahun 2013. Kemudian dari biji kakao tersebut Malaysia dapat mengolahnya menjadi produk olahan yang memiliki value added lebih tinggi. Ketidakmampuan dalam melakukan pengolahan pada kakao mentah tersebut menyebabkan Indonesia kehilangan sejumlah nilai tambah jika saja produk kakao diekspor dalam bentuk olahan. Selain itu, ketidakmampuan dalam proses pengolahan sering kali membuat Indonesia harus mengimpor kembali produk-produk olahan dari hasil ekpor biji kakao tersebut. Akibatnya, neraca perdagangan akan semakin mengecil dan value added kakao yang hilang akan semakin besar.

Secara umum, tidak hanya kakao yang diekspor dalam bentuk bahan mentah. Produk potensial lain seperti karet alam, kopi, dan udang juga masih diekspor dalam bentuk yang sama. Mestinya produk potensial tersebut diekspor dalam bentuk minimal produk setengah jadi agar memiliki value added yang lebih tinggi. Selain itu, pada kawasan sentra produksi komoditas ekspor utama masih sangat jarang dibangun agroindustri. Padahal jika dibangun banyak industri, marjin perdagangan, dan pengangkutan dapat ditekan dan pengangguran dapat dikurangi. Berkaca dari model pembangunan Lewis, sebenarnya revolusi dari sektor tradisional menuju sektor industri harus tetap berbasis pada sektor tradisional yang ada pada masing-masing negara. Negara dengan basis pertanian hendaknya memulai revolusi dengan melakukan industrialisasi dalam sektor tersebut menjadi agroindustri. Selain itu, konsep one village one product (OVOP) yang diterapkan pada sektor pertanian di Jepang juga dapat ditiru untuk diterapkan di Indonesia. 
Salah satu ekspor pertanian yang merupakan komoditas utama adalah kakao. Indonesia adalah negara pengekspor kakao ketiga terbesar di dunia, setelah Pantai Gading dan Ghana. Menurut data Food and Agriculture Organization (FAO) pada tahun 2016, 14,7 persen dari produksi kakao dunia berasal dari Indonesia. Meskipun begitu, jika dilihat dari nilai Revealed Comparative Advantage(RCA) yang merupakan indikator keunggulan komparatif suatu negara dalam memproduksi suatu komoditas dengan alternatif biaya lebih rendah dibanding negara lain untuk komoditas yang sama, kakao Indonesia perkembangannya selalu mengalami penurunan. Setiap tahunnya Indonesia melakukan ekspor kakao. Disamping itu, Indonesia juga mengimpor kakao bahkan jauh lebih besar. Sebagian besar kakao diekspor dalam bentuk mentah dan sebagian besar kakao diimpor dalam bentuk kakao jadi atau olahan. Apabila kakao yang diekspor masih dalam bentuk mentah, nilai ekspornya akan lebih rendah dibandingkan nilai re-import produk tersebut. Hal ini sejalan dengan kebijakan kementerian perindustrian yang secara bertahap ingin menghentikan ekspor yang berupa barang mentah menjadi barang yang sudah diolah. Namun, kebijakan ini baru diterapkan pada bahan mineral dan tambang, sedangkan untuk ekspor berupa barang selain mineral dan tambang masih belum banyak diterapkan. Oleh karena itu, dalam penelitian ini akan dikaji bagaimana perkembangan gap yang dihasilkan dari value added yang hilang akibat ekspor kakao yang berupa barang mentah kemudia re-import kakao tersebut yang sudah mengalami pengolahan. Oleh karena itu, tujuan penelitian ini adalah untuk (1) memperoleh gambaran umum daya saing kakao Indonesia di pasar internasional dan (2) mengkaji perkembangan lost value added akibat ekspor barang mentah dan impor barang jadi dalam komoditas kakao di Indonesia.

\section{METODE PENELITIAN}

Penelitian ini menggunakan data sekunder yang diambil dari publikasi BPS dan FAO. Variabel yang digunakan adalah harga ekspor kakao dalam bentuk bahan mentah dan impor kakao dalam bentuk bahan olahan. Nilai ini didapatkan dari membagi nilai impor atau ekspor dengan berat dengan asumsi perdagangan bersifat multilateral dan tidak ada perbedaan harga antar negara pengimpor. Komoditas kakao yang digunakan mencakup kakao dalam bentuk mentah dan yang telah diolah dengan pendekatan 
Harmonized System (HS) 8 digit. Selang waktu yang digunakan untuk data tahunan digunakan data tahun 2009-2016 dan untuk data bulanan digunakan data tahun 2015-2018. Pengunaan pada periode tahunan tersebut kondisi perekonomian Indonesia yang tidak mengalami krisis dan penerapan standar SNN 2008 yang baru diterapkan, sehingga memiliki pengertian yang sama.

Metode analisis yang digunakan adalah metode analisis deskriptif menggunakan nilai RCA dan peramalan menggunakan ARIMA untuk menjawab perkembangan pendapatan dari vaue added perperiodenya. RCA digunakan untuk menggambarkan daya saing kakao Indonesia di pasar internasional. Cara penghitungan RCA adalah sebagai berikut:

$$
R C A=\frac{X_{i k} / X_{i t}}{W_{k t} / W_{t}}
$$

Di mana:

$X_{\text {ik }}$ : Nilai ekspor komoditas $k$ dari negara $i$

$X_{\text {it }}$ : Nilai ekspor total (produk $k$ dan lainnya) dari negara i

$W_{\mathrm{kt}}$ : Nilai ekspor komoditas k di dunia

$\mathrm{W}_{\mathrm{t}}$ : Nilai ekspor total dunia

Jika nilai indeks RCA suatu negara untuk komoditas tertentu adalah lebih besar dari satu, negara tersebut memiliki keunggulan komparatif. Penghitungan lost value added dilakukan dengan mengurangkan total harga barang mentah yang diekspor perkg (produk kakao dengan kode HS 18010000 dan 18020000) dengan total harga barang olahan yang diimpor perkg (produk kakao selain yang berkode HS 18010000 dan 18020000). Nilai tersebut anggap sebagai lost value added karena menggambarkan nilai barang yang mengalir keluar akibat dari ketidakmampuan dalam mengolah produk secara mandiri.

Autoregressive Integrated Moving Average (ARIMA) digunakan untuk menjawab peramalan dari value added. Variable yang akan diramalkan adalah selisih pendapatan yang hilang dari harga ekspor kakao mentah dan impor kakao yang sudah diolah. Semakin besar selisihnya, semakin besar pula pendapatan Indonesia yang hilang. Dengan ARIMA akan dilihat untuk kedepannya bagaimana perkembangan selisih dari keduannya. Untuk spesifikasi model ARIMA terbaik yang digunakan akan dilihat dari nilai Akaike Information Criteration (AIC) terkecil, Schwarz Information 
Criterion (SIC) terkecil, Squared Standard Error (SSE) terkecil, dan koefisien determinasi $\left(\mathrm{R}^{2}\right)$ terbesar.

\section{HASIL DAN PEMBAHASAN}

Pangsa pasar kakao Indonesia di dunia cukup besar, yaitu tiga besar produsen kakao terbesar di dunia. Tidak mengherankan jika kakao merupakan salah satu dari 10 komoditas unggulan ekspor Indonesia.

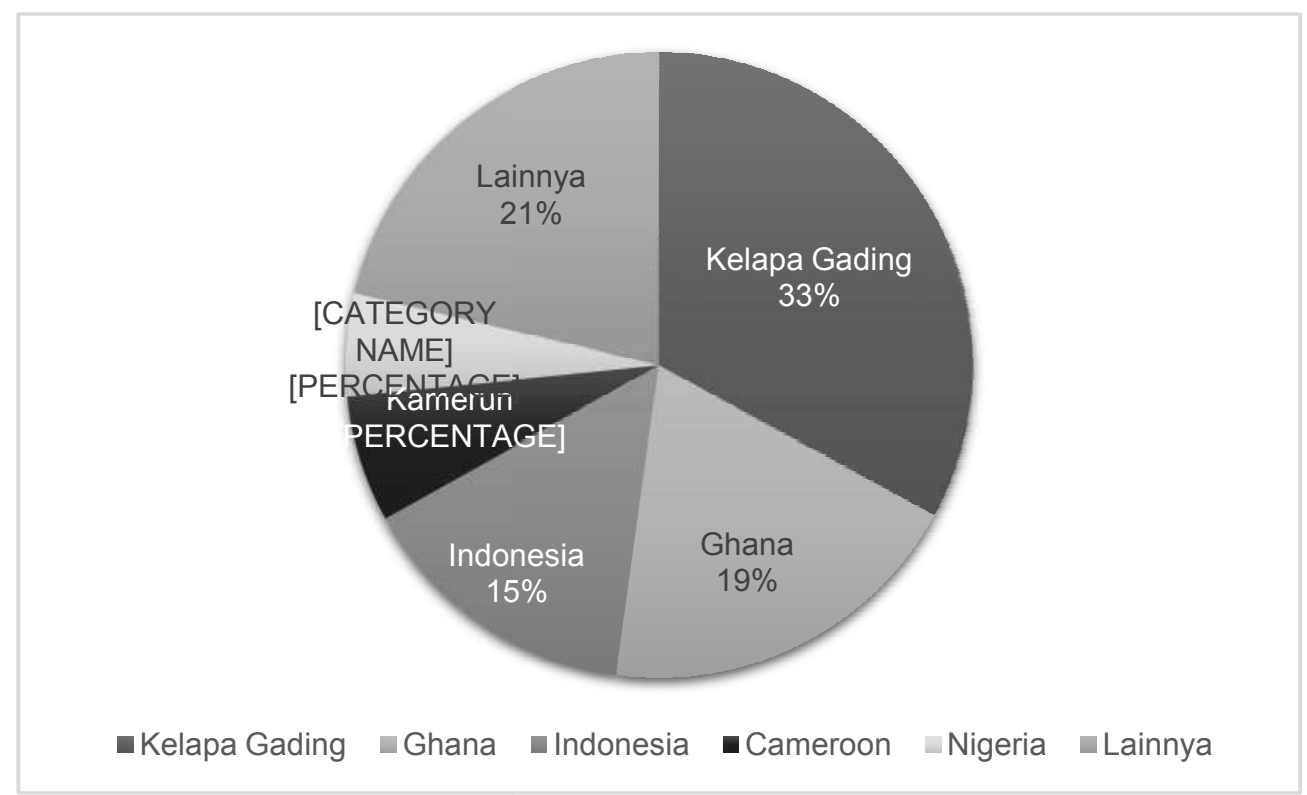

Sumber: FAO, 2016

Gambar 4. Pangsa Pasar Kakao Indonesia dan Lima Negara Eksportir Utama Lainnya Tahun 2016

Berdasarkan Gambar 4, dapat terlihat bahwa pangsa pasar kakao Indonesia cukup besar. Indonesia berada pada posisi tiga terbesar dengan share sebesar 15 persen. Mayoritas pasar dagang kakao Indonesia berada pada kawasan Asia, sedangkan kedua negara tersebut sudah hampir menguasai pasar Eropa (Tresliyana, Fariyanti, \& Rifin, 2015). Posisi Indonesia masih kalah jauh jika dibandingkan dengan Pantai Gading dan Ghana. Meskipun pangsa pasar Indonesia cukup besar, akan tetapi daya saing kakao Indonesia tergolong rendah seperti pada Gambar 5.

Berdasarkan Gambar 5 dapat dilihat bahwa daya saing kakao Indonesia dibandingkan dengan lima negara pengekspor lainnya sangat kecil pada 
tahun 2009-2016. Hal ini dikarenakan kakao Pantai Gading dan Ghana telah mengalami proses fermentasi, sehingga mempunyai nilai tambah yang lebih (Tresliyana, Fariyanti, \& Rifin, 2015).Selain itu, kualitas kakao Indonesia mengalami penurunan akibat efek dari perubahan iklim, serangan hama, dan kurangnya penyuluhan sejak periode tahun 2006-2014. Hal ini berdampak pada produktivitas kakao Indonesia yang mengalami penurunan. Produktivitas kakao Indonesia hanya 0,3-0,4 ton per hektar setiap tahun. Nilai ini masih jauh dibandingkan dengan negara-negara pengekspor utama lainnya yang mencapai 1 ton per hektar setiap tahun. Penurunan produktivitas kakao tersebut mengakibatkan gap antara nilai inpor dan ekspor yang ditimbulkan semakin besar (Gambar 6).

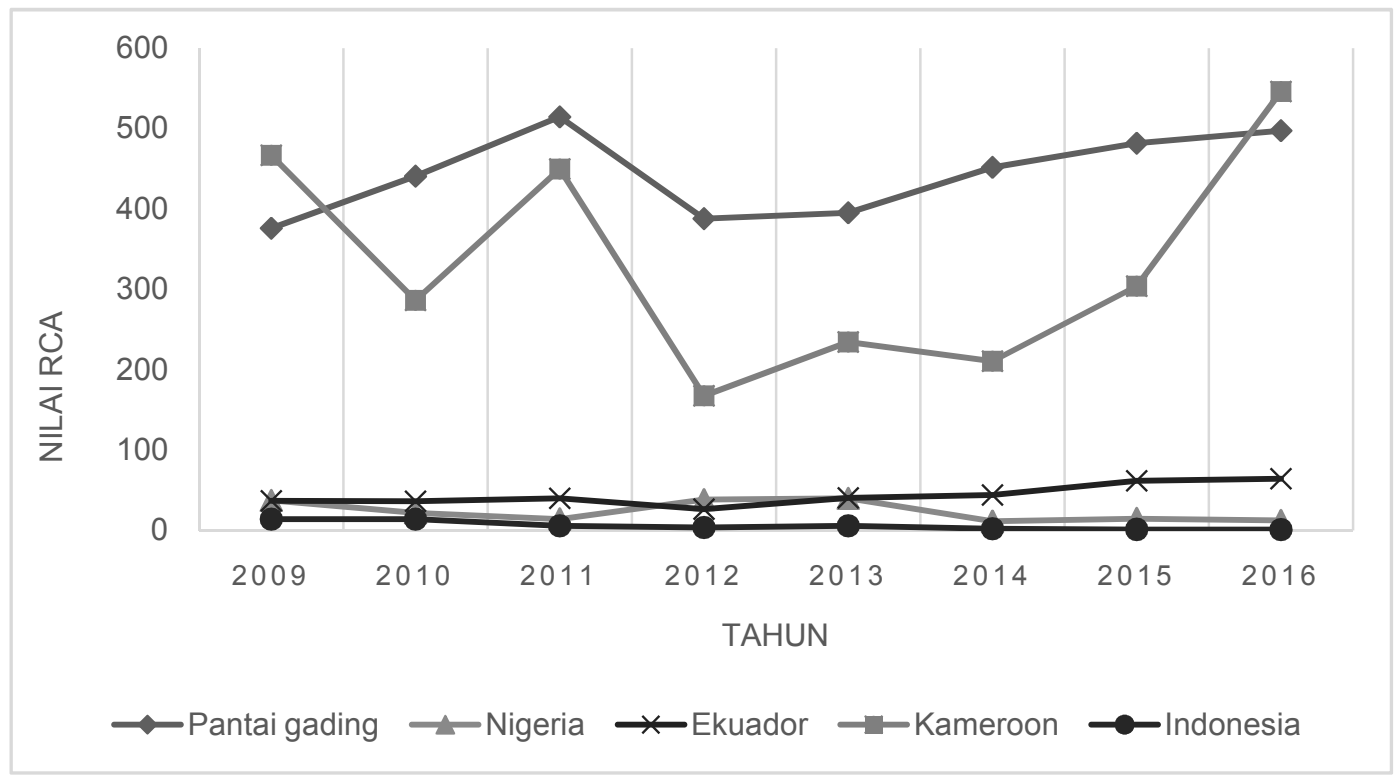

Sumber: FAO, 2016

Gambar 5. Perbandingan RCA Kakao Indonesia dan Lima Negara Eksportir Utama Lainnya Tahun 2009-2016

Berdasarkan Gambar 6, nilai ekspor kakao mentah dan impor kakao olahan Indonesia memiliki pola yang sangat berfluktuatif pada periode Januari 2015 hingga Januari 2018. Dari gambar tersebut dapat dilihat bahwa nilai produk kakao hasil olahan yang diimpor oleh Indonesia jauh lebih besar dibanding nilai kakao mentah yang diekspor. Hal ini menunjukkah bahwa kakao telah mengalami lost value added. Gap antara hasil kakao Indonesia 
yang diekspor dan diimpor hasil olahan kakao semakin besar, terutama pada awal tahun 2016. Sebenarnya jika Indonesia mampu melakukan pengolahan sendiri pada kakao, nilai tambah kakao akan membawa keuntungan bagi Indonesia.

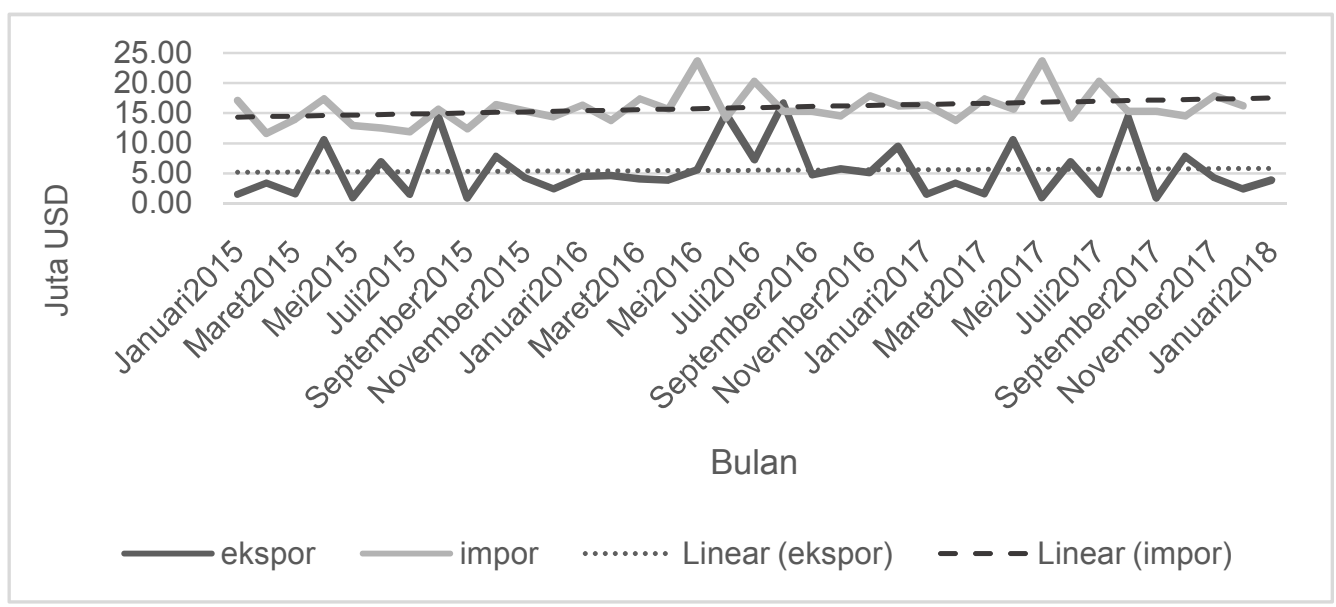

Sumber: BPS, data diolah.

Gambar 6. Gap Antara Nilai Total Ekspor Produk Kakao Mentah dan Impor Produk Kakao Olahan Indonesia Periode Januari 2015-Januari 2018

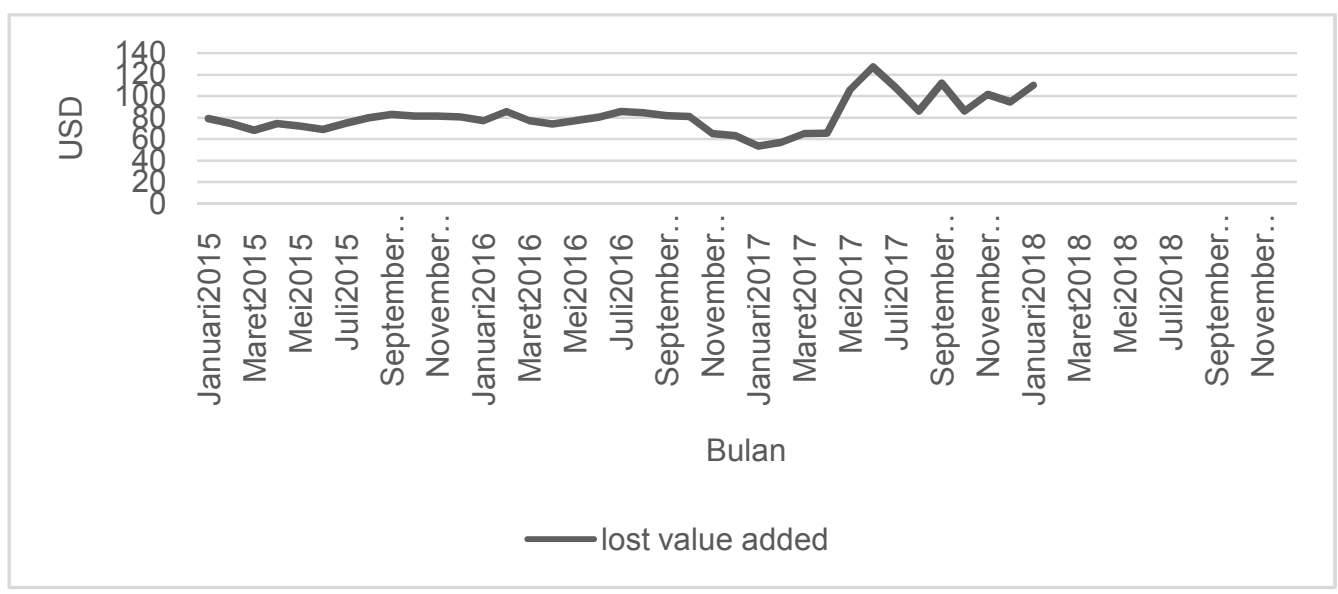

Sumber: BPS, data diolah.

Gambar 7. Perkembangan Lost Value Added Produk Kakao Periode Januari 2015-Januari 2018 
Berdasarkan Gambar 7 nilai lost value added produk kakao Indonesia cenderung stabil pada periode Januari 2015 hingga April 2017. Nilai lost value added menunjukkan tren yang meningkat pada Mei 2017 hingga sekarang. Nilai ini sejalan dengan daya saing, yang dilihat dari nilai RCA, juga mengalami penurunan. Untuk mengatasinya diperlukan kerja sama antarberbagai elemen, baik pembuat kebijakan maupun produsen kakao. Misalnya dengan membatasi ekspor barang mentah secara bertahap dan meningkatkan pembangunan agroindustri. Agroindustri merupakan solusi yang tepat dalam rangka transformasi pertanian kakao. Bagi negara berkembang seperti Indonesia, keterbatasan, baik teknologi maupun modal, menjadi kendala. Akan tetapi, masih ada beberapa solusi lain untuk mengatasi keterbatasan tersebut.OVOP adalah solusi lain untuk memperbaiki sektor pertanian di Indonesia. OVOP telah diimplementasikan di Jepang sejak tahun 1980-an. Hasilnya adalah sektor pertanian di Jepang menjadi lebih maju dibandingkan sektor pertanian di negara-negara berkembang.

Hasil Ramalan Lost Value Added Kakao

Untuk melakukan peralaman diperlukan uji stationeritas data. Berikut adalah hasil uji stationeritas dan korelogram.

Tabel 1. Hasil Uji Stationeritas

\begin{tabular}{lcccccc}
\hline & \multicolumn{3}{c}{ Level } & & \multicolumn{3}{c}{ First Difference } \\
\cline { 2 - 7 } Variabel & $\begin{array}{c}\text { ADF } \\
\text { Stat }\end{array}$ & $\begin{array}{c}\text { Nilai } \\
\text { Kritis 5 } \\
\text { persen }\end{array}$ & Hasil & $\begin{array}{c}\text { ADF } \\
\text { Stat }\end{array}$ & $\begin{array}{c}\text { Nilai } \\
\text { Kritis 5 } \\
\text { persen }\end{array}$ & Hasil \\
\hline LVA & -2.2086 & -2.9458 & $\begin{array}{c}\text { Tidak } \\
\text { Stationer }\end{array}$ & -6.7927 & -2.9484 & Stationer \\
\hline
\end{tabular}

Sumber: Hasil olahan peneliti

Berdasarkan Tabel 1 dapat disimpulkan bahwa LVA tidak stationer pada saat berada di level. Oleh karena itu, perlu dilakukan diferensiasi agar data menjadi stationer. Setelah dilakukan diferensiasi pertama maka data LVA telah stationer. Kemudian, untuk melakukan peramalan diperlukan pendeteksian melalui melalui plot Autocorrelation Function (ACF) dan PartialAutocorrelation Function (PACF) sebagai berikut: 
Tabel 2. Fungsi Korelogram Saat Berada di Level

\begin{tabular}{|c|c|c|c|c|c|c|c|c|}
\hline \multicolumn{2}{|c|}{ Autocorrelation } & \multicolumn{3}{|c|}{ Partial Correlation } & \multirow{2}{*}{$\begin{array}{l}\text { AC } \\
0.640\end{array}$} & \multirow{2}{*}{$\begin{array}{l}\text { PAC } \\
0.640\end{array}$} & \multirow{2}{*}{$\frac{\text { Q-Stat }}{1016.404}$} & \multirow{2}{*}{$\begin{array}{c}\text { Prob } \\
0.000\end{array}$} \\
\hline 1 & $\longmapsto$ & I & $=$ & 1 & & & & \\
\hline 1 & $\square$ & 1 & b 1 & 2 & 0.437 & 0.047 & 24.278 & 0.000 \\
\hline 10 & $\emptyset$ । & 10 & 1 & 3 & 0.209 & -0.148 & 26.138 & 0.000 \\
\hline & b 1 & 1 & 1 & 4 & 0.083 & -0.020 & 26.439 & 0.000 \\
\hline 1 당 & 1 & 1면 & 1 & 5 & -0.132 & -0.243 & 27.221 & 0.000 \\
\hline 10 & 1 & & 曰 & 6 & -0.097 & 0.174 & 27.659 & 0.000 \\
\hline 14 & I & & 1 & 7 & -0.087 & 0.023 & 28.023 & 0.000 \\
\hline 1 든 & 1 & 1 다 & 1 & 8 & -0.116 & -0.157 & 28.691 & 0.000 \\
\hline 1 단 & 1 & 1 & 1 & 9 & -0.159 & -0.059 & 29.997 & 0.000 \\
\hline 10 & 1 & 1 & 1 & 10 & -0.119 & -0.003 & 30.752 & 0.001 \\
\hline 10 & 1 & & b 1 & 11 & -0.094 & 0.047 & 31.245 & 0.001 \\
\hline 10 & 1 & & 1 & 12 & -0.116 & -0.077 & 32.025 & 0.001 \\
\hline 10 & 1 & 1 & 1 & 13 & -0.090 & -0.029 & 32.517 & 0.002 \\
\hline 10 & 1 & 10 & 1 & 14 & -0.093 & -0.082 & 33.062 & 0.003 \\
\hline I & 1 & 1 & 马 & 15 & -0.020 & 0.137 & 33.088 & 0.005 \\
\hline 1 & 1 & 11 & 1 & 16 & -0.002 & 0.015 & 33.089 & 0.007 \\
\hline
\end{tabular}

Sumber: Hasil olahan peneliti

Berdasarkan Tabel 2, fungsi ACF pada lag ke 1 dan 2 melewati Garis Bartlett, sedangkan fungsi PACF hanya pada lag ke 1 yang melewati batas Garis Bartlett. Pada fungsi PACF, lag ke 5 juga hampir melewati batas Garis Bartlett, sehingga perlu dilakukan identifikasi sampai lag ke 5. Pemilihan model terbaik dipilih berdasarkan model yang memiliki nilai AIC dan SIC terkecil. Berikut adalah hasil pemilihan model terbaik.

Tabel 3. Pemilihan Model Terbaik

\begin{tabular}{ccccc}
\hline Model & $\mathrm{R}^{2}$ & AIC & SIC & SSE \\
\hline $\mathrm{AR}(1)+\mathrm{MA}(1)+\mathrm{MA}(2)$ & 0.183195 & 8.015990 & 8.235923 & 4553.083 \\
$\mathrm{MA}(1)+\mathrm{MA}(5)$ & 0.168551 & 7.941078 & 8.117024 & 4634.711 \\
$\mathrm{AR}(1)+\mathrm{AR}(5)+\mathrm{MA}(1)+\mathrm{MA}(5)$ & 0.238962 & 8.008482 & 8.272402 & 4242.224 \\
\hline Sumber: Hasil olahan peneliti & & & &
\end{tabular}

Berdasarkan Tabel 3, model terbaik yang digunakan untuk meramal lost value added kakao selama bulan Januari 2015 sampai dengan Desember 2018 adalah ARIMA $(0,1,5)$. Pemilihan model ini dikarenakan nilai AIC dan SIC yang dihasilkan lebih kecil dibandingkan model lainnya. Pemilihan tidak 
berdasarkan pada $\mathrm{R}^{2}$ karena sifat nilai koefisien determinasi akan semakin besar saat terjadi penambahan variabel. Pada pemilihan dua model nilai $\mathrm{R}^{2}$ lebih besar karena ada unsur autoregressive (AR). Berikut adalah hasil dari model terbaik.

Tabel 4. Model Terbaik (Moving Average)

\begin{tabular}{lllll}
\hline \hline Variable & Coefficient & Std. Error & t-Statistic & Prob. \\
\hline \hline C & 0.741736 & 0.790998 & 0.937722 & 0.3554 \\
MA(1) & -0.330177 & 0.116659 & -2.830267 & 0.0080 \\
MA(5) & -0.336750 & 0.142921 & -2.356200 & 0.0248 \\
SIGMASQ & 128.7420 & 25.96694 & 4.957919 & 0.0000 \\
\hline \hline R-squared & 0.168551 & Mean dependent var & 0.864025 \\
Adjusted R-squared & 0.090603 & S.D. dependent var & 12.62000 \\
S.E. of regression & 12.03473 & Akaike info criterion & 7.941078 \\
Sum squared resid & 4634.711 & Schwarz criterion & 8.117024 \\
Log likelihood & -138.9394 & Hannan-Quinn criter. & 8.002488 \\
F-statistic & 2.162342 & Durbin-Watson stat & 1.894300 \\
Prob(F-statistic) & 0.111785 & & & $-.59-.47 \mathrm{i}$ \\
\hline \hline Inverted MA Roots & .88 & $.32+.75 \mathrm{i}$ & $.32-.75 \mathrm{i}$ & \\
\hline \hline
\end{tabular}

Sumber: Hasil olahan peneliti

Berdasarkan Tabel 4, dengan model tersebut diperoleh hasil bahwa selama 11 (sebelas) bulan ke depan, nilai dari lost value added kakao Indonesia diperkirakan akan terus meningkat. Peningkatan nilai lost value added menunjukkan bahwa potensi value added kakao Indonesia cukup besar jika dimanfaatkan dan dikelola dengan baik. Berikut adalah hasil nilai ramalan lost value added kakao: 
Berdasarkan Gambar 8 dapat dilihat bahwa tren nilai tambah yang hilang produk kakao Indonesia semakin naik. Jika kondisi ini tetap dibiarkan, akan semakin banyak potensi pendapatan hasil ekspor kakao yang hilang. Ditambah lagi ekspor kakao yang masih dalam bentuk mentah, yaitu berupa biji kakao, memiliki value added yang rendah. Sebenarnya Industri kakao olahan di Indonesia sudah mulai bermunculan, akan tetapi industri tersebut masih beroperasi jauh di bawah kapasitas produksinya. Hal ini dikarenakan industri kakao di Indonesia masih terkendala dengan suplai bahan baku berupa biji kakao baik dalam kuantitas maupun dalam kualitas yang memadai (Mulyono, 2016)

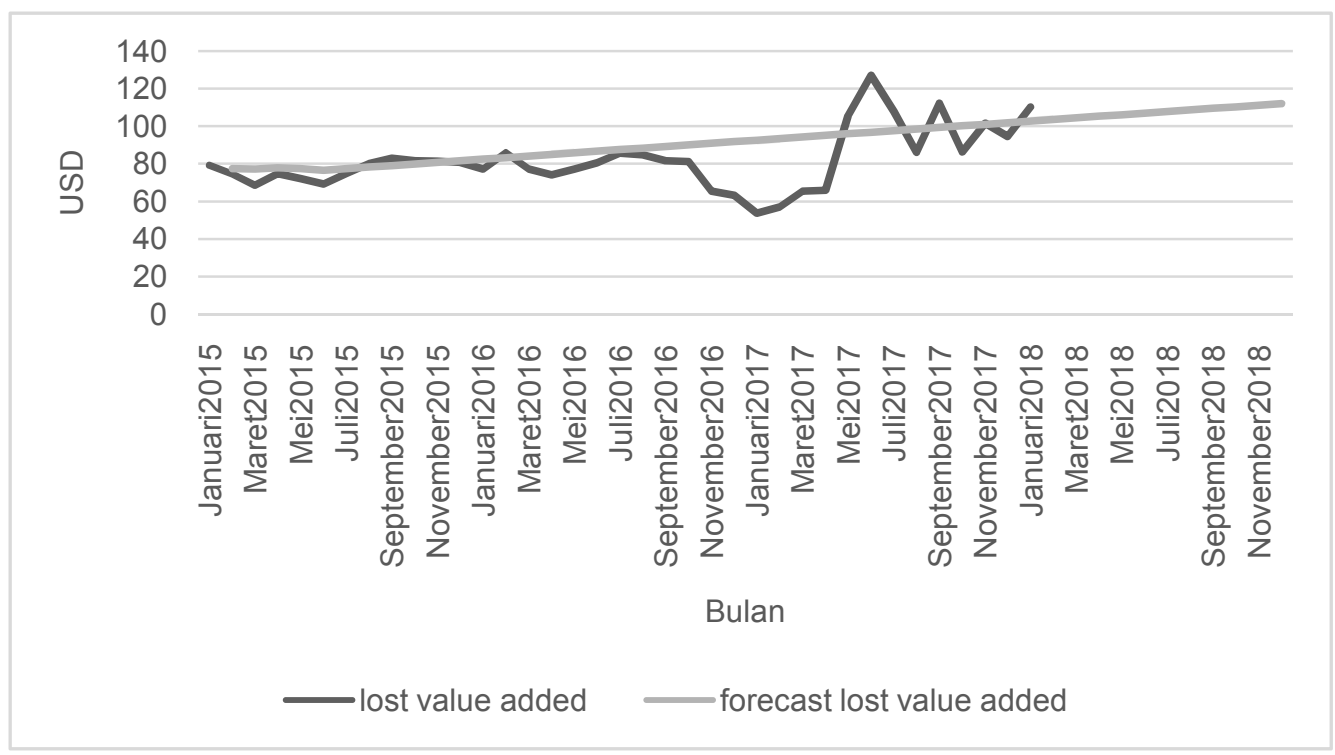

Sumber: BPS, data diolah

Gambar 8. Perkembangan Lost Value Added Produk Kakao Periode Januari 2015-Desember 2018

Memang secara kuantitas, industri pengolahan akan jauh lebih unggul dibandingkan sektor pertanian. Akan tetapi, pengimplementasian industri pengolahan kakao di Indonesia selama ini belum tepat. Seharusnya industri pengolahan kakao dibangun dalam bentuk agroindustri. Pembangunan industri langsung di daerah sentra kakao. Transformasi pertanian menjadi agroindustri kakao perlu dilakukan secepat mungkin jika tidak ingin Indonesia kehilangan lebih banyak pendapatan hasil 
ekspor kakao. Apalagi nilai RCA Indonesia yang masih jauh di bawah negara pekspor utama seperti Pantai Gading dan Kamerun. Belum lagi kegemaran masyarakat Indonesia yang mencintai produk coklat olahan negara lain seperti Swiss yang akan semakin mengurangi pendapatan hasil ekspor kakao (re-import of the exported product). Berikut adalah peramalan akibat kegemaran masyarakat Indonesia yang lebih menyukai impor kakao dalam bentuk olahan.

Tabel 4. Hasil Ramalan Lost Value Added Produk KakaoPeriode FebruariDesember 2018

\begin{tabular}{cc}
\hline Bulan & Lost Value Added (USD) \\
\hline Februari & 106.4805812 \\
Maret & 107.2223172 \\
April & 107.9640532 \\
Mei & 108.7057892 \\
Juni & 109.4475252 \\
Juli & 110.1892612 \\
Agustus & 110.9309971 \\
September & 111.6727331 \\
Oktober & 112.4144691 \\
November & 113.1562051 \\
Desember & 113.8979411 \\
\hline
\end{tabular}

Sumber: BPS, data diolah

Berdasarkan Tabel 4, nilai tambah kakao yang hilang semakin bertambah. Setiap $1 \mathrm{~kg}$ kakao mentah yang diekspor yang kemudian diimpor kembali ke Indonesia dalam bentuk olahan sekitar USD113,89 atau sekitar 1.613.478,23 dengan menggunakan kurs saat ini (Rp14.166). Dengan kata lain, Indonesia telah kehilangan pendapatan sebesar Rp1,6 juta untuk $1 \mathrm{~kg}$ kakao yang diekspor dalam bentuk mentah. Nilai yang cukup besar yang sebenarnya dapat dimanfaatkan ekspor kalao dalam bentuk olahan. Dapat dibayangkan bagaimana jika Indonesia mengimpor 1000 ton kakao ke seluruh dunia. Tentunya, Indonesia kehilangan pendapatan sekitar Rp1,6 triliun. Nilai yang sangat fantastis untuk memperbaiki pembangunan di Indonesia khususnya dalam bidang pertanian kakao.

Diperlukan upaya untuk memperbaiki sektor pertanian Indonesia menjadi lebih modern. Salah satu transformasi sektor pertanian yang dapat 
dilakukan misalnya seperti pembangunan agroindustri di sentra produksi. Adanya agroindustri akan mengurangi biaya produksi dan juga dapat mengurangi ketimpangan dan pengangguran di daerah perdesaan. Konsep inilah yang menjadi concern dalam teori perubahan struktural Lewis. Artinya sektor pertanian tidak bener-benar ditinggalkan, akan tetapi dikembangkan menjadi sektor yang jauh lebih modern. Untuk mendukung agroindustri dapat dilakukan kerja sama dengan beberapa elemen terkait seperti Kementerian Desa, Pembangunan Daerah Tertinggal, dan Transmigrasi. Bantuan Kemendesa dan PDT melalui alokasi dana desa akan membantu proses transformasi sektor pertanian tersebut sekaligus pengimplementasian konsep OVOP.

Untuk saat ini, pembuatan agroindustri dan pengimplementasian OVOP memang membutuhkan waktu yang tidak sedikit. Permasalahannya adalah pada insentif harga. Harga untuk pengolahan dalam negeri bisa menjadi lebih tinggi dibandingkan melakukan impor. Hal ini dikarenakan untuk mendatangkan alat dan teknisi yang ahli juga membutuhkan biaya yang tidak sedikit. Selain itu, blending untuk menjadi coklat tergantung selera masyarakat Indonesia. Umumnya masyarakat Indonesia masih belum paham betul membuat taste coklat agar digemari dan laku keras di pasar. Saat ini masyartakat Indonesia sudah telanjur menikmati coklat buatan luar negeri dengan taste yang enak dan harga yang cukup terjangkau.

\section{SIMPULAN DAN SARAN}

Indonesia, sebagai negara pengekspor kakao terbesar ketiga di dunia, memiliki daya saing kakao yang terus menurun setiap tahunnya. Nilai tambah ekspor kakao juga terus menuru karena ekspor kakao Indonesia sebagian besar masih barang mentah atau biji kakao sehingga nilai tambahnya kecil selain itu indonesia juga terus melakukan impor kakao dalam bentuk olahan sehingga nilai tambah ekspor kakao semakin hilang".Setelah dilakukan forecasting, selisih dari nilai yang hilang dari ekspor kakao mentah dan impor kakao olahan terus meningkat. Hasil ramalan ini menunjukkan bahwa akan jauh lebih menguntungkan jika Indonesia dapat melakukan pengolahan sendiri produk kakao dan mengekspornya ke pasar internasional, sehingga kakao dapat menjadi potensi value added untuk perekonomian nasional. 
Saranbagi pemerintah, perlu mulai dikembangkan lagi berbagai alternatif agroindustri yang berbasis produksi, khususnya komoditas kakao. Kakao indonesia bisa diolah terlebih dahulu sehingga memiliki nilai yang lebih tinggi. Selain itu, diperlukan sosialisai dan pengimplementasiaon konsep OVOP pada sektor pertanian agar meningkatkan produktivitas dan meminimalkan persaingan domestik. Meskipun demikian, penelitian ini masih bersifat agregat dan tidak mempertimbangkan faktor lain seperti regulasi pemerintah. Selain itu, penelitian ini adalah penelitian pertama yang dilakukan di Indonesia, sehingga perlu dikembangkan lebih lanjut untuk dapat dijadikan sebagai role model dalam kebijakan pemerintahan.

\section{DAFTAR PUSTAKA}

Agusalim, L. (2017). DAMPAK PAJAK EKSPOR TERHADAP PENINGKATAN NILAI TAMBAH: STUDI EMPIRIS AGROINDUSTRI DI INDONESIA (Export Tax Effects on Value Added Enhancement: An Empirical Study of Indonesia's Agroindustry). Jurnal Ekonomi \& Kebijakan Publik, 27-40.

Badan Pusat Statistik. (2018). Buletin Statistik Perdagangan Luar Negeri Ekspor Desember 2017. Jakarta: BPS.

Badan Pusat Statistik. (2018). Buletin Statistik Perdagangan Luar Negeri Impor Desember 2017. Jakarta: BPS.

Bisnis Indonesia. (2017, September 5). Diperoleh tanggal 5 Mei 2018, dari http://industri.bisnis.com/read/20170905/257/687081/industrikekurangan-pasokan-kakao

detikcom. (2014, April 15). Diperoleh tanggal 5 Mei 2018, dari https://finance.detik.com/industri/2555516/serap-67-ekspor-kakaori-malaysia-jadi-produsen-cokelat-dunia

detikcom. (2014, April 15). Diperoleh tanggal 5 Mei 2018, dari https://finance.detik.com/industri/d-2555458/produksi-kakao-riterus-merosot-selama-8-tahun-terakhir

FAO. (2015, Februari). Chocolate: Facts and figures. Diperoleh tanggal 5 Mei 2018, dari http://www.fao.org/resources/infographics/infographicsdetails/en/c/277756/ 
FAO. (2016, November). FAOSTAT. Diperoleh 5 Mei 2018, dari http://www.fao.org/faostat/en/\#data/QC.

Mulyono, D. (2016). Harmonisasi Kebijakan Hulu-Hilir dalam Pengembangan Budidaya dan Industri Pengolahan Kakao Nasional. Jurnal Ekonomi \& Kebijakan Publik,7 (2), 185-200.

Permana, S. H., \& Izzaty. (2010). Daya saing ekspor barang - barang dari karet. Jurnal Ekonomi \& Kebijakan Publik, 2(1), 153-188.

Rasbin, \& Ginting, A. M. (2011). 495 Upaya Peningkatan Ekspor Sektor Usaha Mikro, Kecil Dan Menengah Melalui Peningkatan Daya Saing Produk. Jurnal Ekonomi \& Kebijakan Publik, 2(1), 495-526.

Tresliyana, A., Fariyanti, A., \& Rifin, A. (2015). Daya Saing Kakao Indonesia di Pasar Internasional. Jurnal Manajemen \& Agribisnis, 12(2), 150-162.

Todaro, M. P., \& Stephen, C. S. (2015). Economic Development Twelfth Edition. New Jersey: Pearson. 